\title{
МАТЕМАТИЧЕСКАЯ МОДЕЛЬ САУ ВЕНТИЛЯТОРНОЙ ГРАДИРНИ
}

Гришаев Н.А. ${ }^{1}$

${ }^{1}$ ГВУЗ «Донецкий национальный технический университет», Донецк

Copyright (C) 2014 by author and the journal "Automation technological and business - processes". This work is licensed under the Creative Commons Attribution International License (CC BY). http://creativecommons.org/licenses/by/4.0/

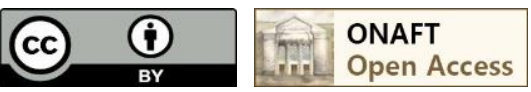

DOI: $10.15673 /$

\begin{abstract}
Аннотация
Рассматривается система автоматического управления вентиляторной градирни. Представлена функцинальная схема градирни. С помощью программы для моделирования, имитации и анализа динамических систем MATLAB\&SIMULINK промоделирована модель вентиляторной градирни с учетом двух возмущений: влажность воздуха и температура горячей воды.
\end{abstract}

\section{Abstract}

The system of automatic control of mechanical-draft tower is examined. The functional diagram of cooler is presented. By the program for a design, imitation and analysis of the dynamic systems of Matlab\&simulink the model of mechanical-draft tower is modelled taking into account two indignations: humidity of air and temperature of hot water.

Ключевые слова

Градирня, возмущение, автоматизация, функциональная схема. Общая постановка проблемы

В горнодобывающей, нефтеперерабатывающей, стекольной, химической промышленности, машиностроении, металлургии и других отраслях, на крупных предприятиях, большое значение имеет проблема охлаждения оборотной воды, применяемой в замкнутом технологическом цикле, до требуемой температуры. Необходимость поддержания требуемой разности температуры, обуславливается спецификой некоторых химических производств, в которых необходимо обеспечить точность технологического цикла. На крупных предприятиях широкое распространение получили градирни.

Градирня - это сооружение для охлаждения воды атмосферным воздухом. Горячая вода в градирне охлаждается как за счет контакта с холодным воздухом, так и в результате так называемого испарительного охлаждения в процессе испарения части потока воды [1,2].

Основными возмущениями, которые оказывают влияние на температуру охлажденной воды, являются [3]:

- перепад температур горячей/охлаждённой воды;

- температура окружающего воздуха;

- влажность воздуха;

- подача насоса;

- температура подаваемой горячей воды.

Цель: Повышение эффективности водооборотной системы охлаждения технологического оборудования за счет разработки системы автоматического управления вентиляторной градирней. 


\section{7 СТУДЕНТСЬКА НАУКА}

Функциональная схема вентиляторной градирни

Для повышения эффективности технологического процесса охлаждения воды и обеспечения энергоснабжения в периоды пониженной нагрузки на охладительные установки целесообразно внедрение автоматизированных систем управления технологическими процессами (АСУ ТП) водооборотных циклов.

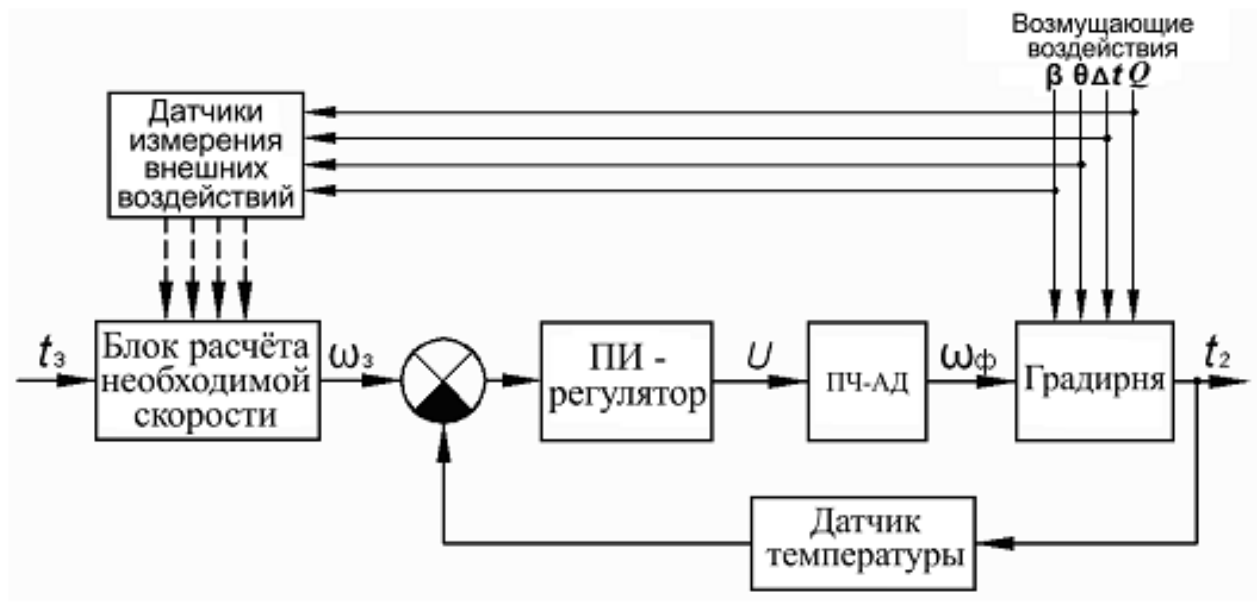

Рис. 1. Функциональная схема вентиляторной градирни

Системы управления по возмущению характерны тем, что управляющий сигнал формируется в зависимости от возмущающих воздействий и уменьшает их влияние на выходную величину объекта компенсацией. Однако учесть и точно измерить все случайные возмущения на практике невозможно. Поэтому для точной стабилизации температуры охлаждённой воды на выходе градирни необходимо использовать комбинированную замкнутую САР с контуром частоты вращения вентилятора.

На основании функциональной схемы, представленной выше и математических моделей составлена структурная схема вентиляторной градирни в программе для моделирования, имитации и анализа динамических систем MATLAB\&SIMULINK (рис. 2).

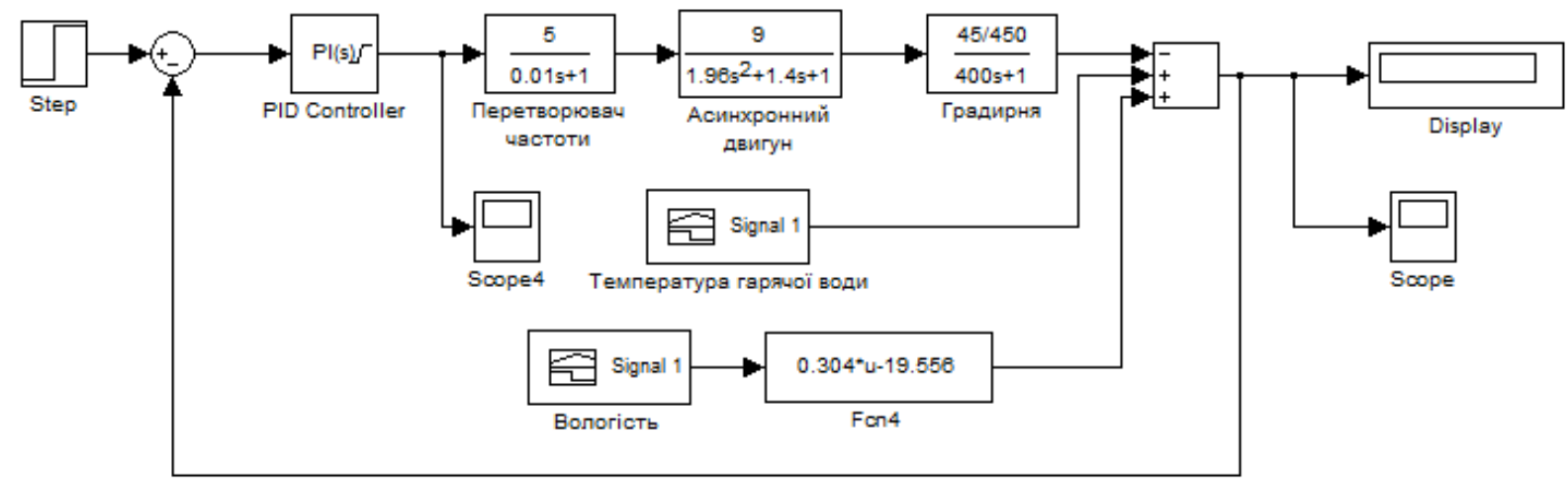

Рис. 2. Схема моделирования вентиляторной градирни в MATLAB\&SIMULINK

В процессе моделирования вентиляторной градирни, с учетом ступенчатых возмущений (температура горячей воды и влажность воздуха) были получены графики переходных процессов, представленные на рис. 3. 


\section{7 СТУДЕНТСЬКА НАУКА}

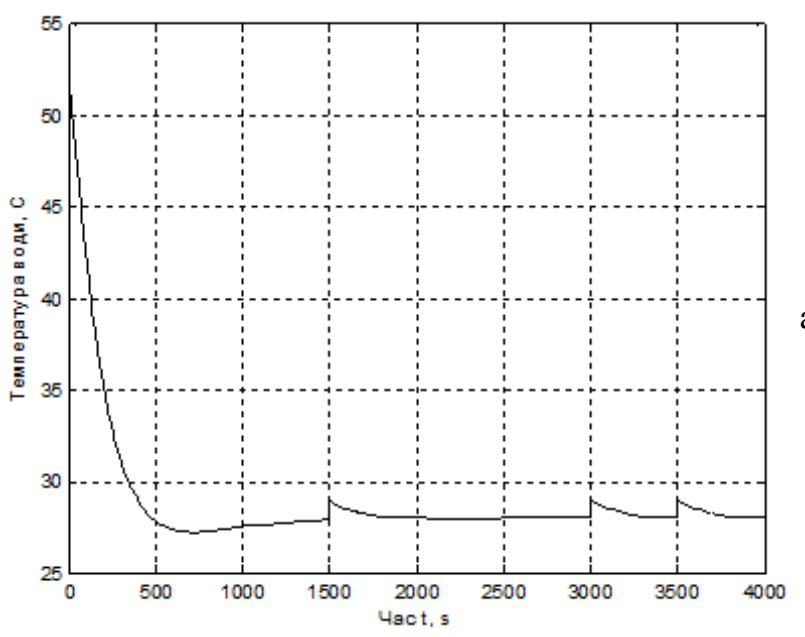

a)

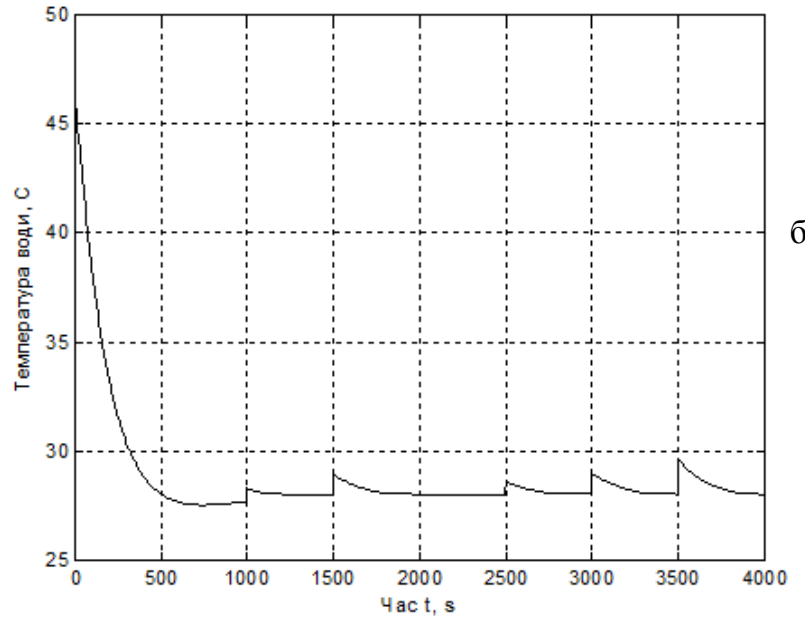

б)

а) реакция САУ вентиляторной градирни на возмущение - температура горячей воды, б) реакция САУ вентиляторной градирни на возмущение - температура горячей воды и влажность воздуха.

Рис. 3. Графики переходных процессов в системе

Проанализировав полученные графики можно сделать вывод, что разработанная система остается устойчивой и показатели качества переходных процессов удовлетворяют техническому регламенту.

\section{Выводы}

1. Разработана функциональная схема вентиляторной градирни;

2. Методом компьютерного моделирования получены графики переходных процессов с учетом двух возмущений. Анализ результатов моделирования подтверждает соответствие качественного поведения модели основным характеристикам исследуемого технологического процесса.

Научный руководитель: Чернышев Н.Н., к.т.н., доц., доцент кафедры автоматики и телекоммуникаций

\section{Литература}

1. Пономаренко В.С. Градирни промышленных и энергетических предприятий /В.С. Пономаренко, Ю. И. Арефев. - М.: Энергоатомиздат, 1998.- 376 с.;

2. Рульнов А.А. Автоматизация систем водоснабжения и водоотведения/ А.А. Рульнов, К.Ю. Евстафьев М.: МГСУ , 2005.- 203c.;

3. Вахромеев И.Е. Автоматизированное управление процессами в охладительных установках / И.Е. Вахромеев, Ю.Б. Евчина // Вестник ЮУрГУ. Серия Компьютерные технологии, управление, радиоэлектроника. - № 8, 2008. - С. 50-53. 